The most relevant chapters for psychiatrists in this fascinating book are those by Michela Summa, Thomas Fuchs and Till Grohmann. Summa argues that even though it is true that there is a distinction and a discontinuity between reality and fiction, reality shapes fiction and the experience of fiction too acts to reconfigure our sense of reality. This chapter does not deal directly with the discontinuities between 'psychotic' reality and everyday reality, but it is clear that much of what is explored is relevant to an understanding of how patients traverse the differing worlds and may also help to illustrate the interpenetration of psychotic reality and everyday experiences. Fuchs focuses on what he terms the 'as-if' function; this is the human cognitive function that allows us 'to suspend the force and validity of the immediate experience and to enter a parallel world of imagination, daydreaming, hypothetical thought, fiction, pretence, role play or theatre'. Fuchs' case is that impairment of this cognitive function underlies the concrete attitude, delusions and what he terms 'transitivism' (the threat of loss-of-self that is posed by the presence of others) in schizophrenia. I am not persuaded by his arguments but nonetheless his is a novel approach. Finally, Grohmann disputes the role of the disturbance of Theory of Mind in schizophrenia and autism and argues for an account based on the phenomenology of intersubjectivity. There's no doubting the fact that the case being put forward is not persuasive but it illustrates that, even in a condition such as autism where certain empirical facts are settled and established, alternative accounts are still possible.

This is a densely written book that has a lot to offer, but it is not for a general audience. Matters that have a central place in psychiatric thought are treated with seriousness and rigour alongside approaches that will surprise many psychiatrists whilst at the same making the subject seem fresh and vital.

Femi Oyebode, Consultant Psychiatrist, National Centre for Mental Health, 25 Vincent Drive Edgbaston, Birmingham B152FG, UK. Email: f.oyebode@nhs.net

doi:10.1192/bjp.2019.61

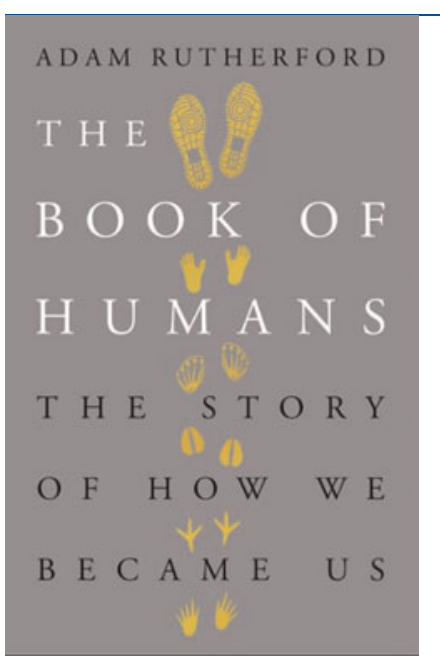
The Book of Humans: The
Story of How We Became Us

By Adam Rutherford. Weidenfeld \& Nicolson. 2018. 272 pp. £18.99 (hb). ISBN 9780297609407

Adam Rutherford is a geneticist who may be better known as a science broadcaster on Radio 4 and for his previous books about genetics for a lay audience. In this book, Rutherford focuses on Homo sapiens as animals, whose genetic endowment gives rise to strong similarities with other animals, but also significant differences. In the first half of the book, Rutherford describes many examples of animal behaviour that some might consider uniquely human, such as tool use, cultural transmission of behaviour and the full range of non-reproductive sexual activity.

It is in the second half that Rutherford examines the human capabilities that enable the modern mind, and which do seem to be unique to humans in terms of degree and complexity; namely symbol formation, linguistic capacity and what psychiatrists would call 'mentalising skills' i.e. the capacity to make inferences about other people's minds and intentions and to see them as real. He cites research that indicates that the capacity for the modern mind seems to have evolved long before it was put into use; that there was a kind of delay before we were able to use these skills to become sapient.

This is an easy book to read and Rutherford has a warm and passionate voice as a science writer. He reminds us that genes only encode proteins and that there are no genes for complex behaviours; rather, it is the cultural evolution by which we teach others what we know that enables humans to create themselves as humans and develop across time. He insists that cultural and biological evolution cannot be separated and emphasises the interdependence of all organisms, concluding that we can be proud of our animal heritage and marvelling at the complexity of life on earth.

A book for the lay reader must always risk dealing with big domains of knowledge superficially, and the book is less successful in its reflections on the modern mind than on the wonders of animal behaviour. But it is an enjoyable read; not least for some very funny lines like 'we [humans] spend a titanic amount of time trying to touch each other's genitals', which makes the genetics department of University College London sound like an interesting place to work.

Gwen Adshead, Consultant Forensic Psychiatrist, Hampshire Pathfinder Service, Southern Health NHS Foundation Trust, HMAPPS, Ravenswood House, Mayles Lane Fareham, Southampton, Hants P017 5NA, UK.

Email: g.adshead@nhs.net

doi:10.1192/bjp.2019.62

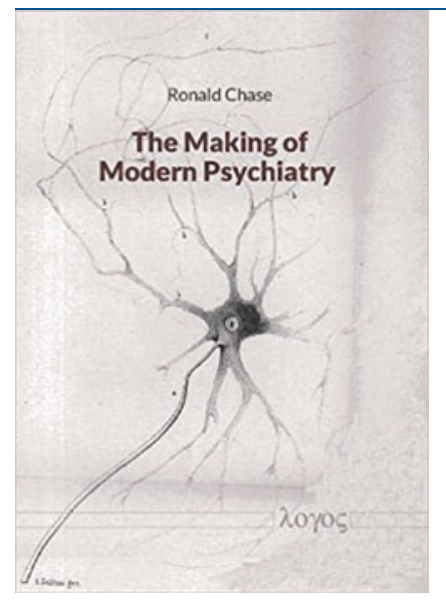

\section{The Making of Modern Psychiatry}

By Ronald Chase. Logos Verlag Berlin. 2018. 232 pp. $£ 31.00$ (pb). ISBN 9783832547189

German psychiatrist Emil Kraepelin (1856-1926) suffered several tragedies, including the death of three of his children in early childhood. He was an avid traveller of Europe and Africa. He became teetotal, convinced that alcohol weakened the will and caused intellectual stupefaction and moral insanity. To record objectively the clinical features of all his patients, he created his famous card index since clinical notes slipped from his grasp when patients moved between hospitals. In his later years Kraepelin acknowledged that the distinction between 'dementia 